\title{
VTD-PACE Regimen
}

National Cancer Institute

\section{Source}

National Cancer Institute. VTD-PACE Regimen. NCI Thesaurus. Code C136269.

A chemotherapy regimen consisting of dexamethasone, thalidomide, cisplatin, doxorubicin, cyclophosphamide and etoposide (DT-PACE), plus bortezomib (VTD-PACE) that is used for the treatment of plasma cell myeloma. 